(RESEARCH ARTICLE)

\title{
Impact of household cooking on release of fluorinated compounds PFOA and PFOS from Tefal coated cookware to foods
}

\author{
AbulFadl Mostafa Mohamed ${ }^{1}$, Sharaf Ashraf Mohamed ${ }^{2}$, Mostafa Mahmoud Mostafa ${ }^{1}$ and El-Saeid \\ Mohamed Hamza 1,3,* \\ ${ }^{1}$ Faculty of Agriculture, Food Science and Technology Dept., Al-Azhar University, Cairo, Egypt. \\ ${ }^{2}$ Faculty of Agriculture, Food Science and Technology Dept., Faculty of Agriculture, Dumyat University, Dumyat, Egypt. \\ ${ }^{3}$ College of Food and Agricultural Sciences, King Saud University, Riyadh, Kingdom of Saudi Arabia.
}

Publication history: Received on 09 August 2018; revised on 19 September 2019; accepted on 20 September 2019

Article DOI: https://doi.org/10.30574/wjarr.2019.3.2.0060

\begin{abstract}
Perfluorinated compounds (PFCs) have taken worldwide attention in recent years. Several PFCs are being used in manufacturing food contact materials, including non-stick coatings (polytetrafluoroethylene (PTFE) or Teflon) for cookware and also their use in paper coatings for oil- and moisture-resistant. PFCs are suggested as a new class of Persistent organic pollutant (POP), where they are chemical stability and do not degrade well naturally hence may accumulate in the body and poses problems for human safety. Thus, it is necessary to assess the migration of PFCs from food contact articles to food under typical cooking conditions. The main objective of this investigation was to study the effect of cooking at prolonged use (repeating for ten times) in household Tefal utensils on leaching PFOA and PFOS compounds from the Teflon layer which coats the inner surface of utensils to food-contact such as tomatoes fruit as the acidic food and white dry beans as the non-acidic food without and with adding of table salt. Also, measurement the surface morphology of Tefal layer before and after cooking by using small shapes as a pattern of Tefal cookware which analyzed by X-ray Diffraction (XRD) and X-ray Microanalysis (EDX), as well Environmental Scanning Electron Microscopy (ESEM). The obtained results indicated that, when the repeat of cooking increased from 1 up to 10 times, the amounts of Perfluorinated compounds (PFOS and PFOA, especially PFOS) were progressively increased in the food contact (tomatoes paste or white dry beans) from the Tefal cookware. On the other side, the addition of table salt to the tested samples at all repeats of cooking (1,5 and 10 times) caused a highly leaching of perfluorinated compounds from the Teflon layer to food-contact more than the same tested samples at the same conditions without salt. Therefore, the acidic food such as tomatoes paste was more effect on the amounts of both PFOS and PFOA in the food-contact than the non-acidic food. Before that, the ESEM images of coating surface of Tefal layer after repeat of cooking exhibited some damage.
\end{abstract}

Keywords: Perfluorinated chemicals; PFOS and PFOA; PTFE coatings; Tefal non-stick cookware

\section{Introduction}

One of the edible oil broadly known is coconut oil. Its source is from the kernel or meat of mature coconuts harvested Perfluorinated compounds (PFCs) are a large group of compounds in which substituted by fluorine in all hydrogencarbon bonds. Due to their chemical properties that include thermal and chemical stability, amphiphilicity, nonflammability and surface-active properties, they have been used in many industrial and consumer applications including adhesives, cosmetics, cleaners, electronics, paper products and coatings material for non-stick cookware [1, $2,3]$.

\footnotetext{
${ }^{*}$ Corresponding author

E-mail address: elsaeidm@ksu.edu.sa
} 
Recently, PFCs have received a lot of attention due to their wide distribution in the environment as result to this widespread usage whereas millions of kilograms of these compounds have been produced worldwide annually. But these compounds are suggested as a new class of persistent organic pollutant (POP) because presence of strong C-F bonds makes them chemically and thermally very stable, resistant to hydrolysis, photolysis, microbial degradation or metabolism hence may accumulate in the body and poses problems for human safety $[4,5,6]$. Thus, it is necessary to assess the migration of PFCs from food contact articles to food under typical cooking conditions [7].

PFCs include perfluorocarboxylic acids such as (PFOA, which include carboxyl functional groups and perfluoroalkane sulfonates such as (PFOS, which include sulfonyl functional groups [8]. PFOA and PFOS are commonly found PFCs in the environment and in the human body [9]. They are stable to hydrolysis in the environment based on half-lives of 41 and 92 years, respectively [10]. Therefore, concerns regarding the safety and impact to human health of PFOA and PFOS are increasing. Currently, there are insufficient data to conclude an effect on human health, although PFOA and PFOS have been found to be teratogenic and hepatotoxic in mouse $[11,12,13,14]$.

PFOS and PFOA are able to bio-accumulate and very slowly eliminate from the body in humans with a half-life of approximately nine and four years, respectively. Regarding the toxicokinetics; they are readily absorbed after oral exposure and are found in the liver, kidneys and blood with lower levels in many other organs, including the central nervous system [10]. Animal studies on PFOS and PFOA showed the etiology of a variety of disorders including diabetes, cerebrovascular disease, neurotoxicity, immune deficiency and cancer. In addition to adverse effects on thyroid function and on the liver including hypertrophy, changes in enzyme activities and increases in absolute or relative liver weight $[15,16]$.

Exposure to PFOS and PFOA may occur directly due to their manufacture and use in commercial products $[17,18]$. Indirect exposure may also occur through the release of perfluorooctane sulfonate (PFOS) and perfluorooctanoic acid (PFOA) precursors that degrade to PFOS and PFOA, released into the environment during production and from treated commercial products $[19,20]$. The European Food Safety Authority (EFSA) has set the tolerable daily intakes (TDI) of PFOS and PFOA at $150 \mathrm{ng} / \mathrm{kg} /$ day and $1500 \mathrm{ng} / \mathrm{kg} /$ day, respectively [9].

PFCs are frequently used in food contact including polytetrafluoroethylene (PTFE) that is used as an inner coating material in nonstick cookware and packaging. PTFE is mostly well known by the DuPont brand name Teflon. This unique polymer coating prevents food from sticking in the pans during the cooking process thus cookware is also easy to wash. At normal cooking temperatures, PTFE-coated cookware can release various gases and chemicals of perfluorinated compounds that present mild to severe toxicity $[21,22,23]$.

So the food can become contaminated with perfluorinated compounds directly from food packaging, since perfluorinated compounds are commonly used in consumer products as stain/water/grease repellents in cooking utensils as nonstick coating and in food contact materials as a coating. Therefore, the studies should be carried out to determine the migration of PFCs from food packaging materials and nonstick cookware to several types of foods [24, 25].

The main objective of the present investigation was to study the effect of cooking at prolonged use (repeating for ten times) in household Tefal utensils on leaching PFOA and PFOS compounds from the teflon layer which coats the inner surface of utensils to food-contact such as tomatoes fruit as the acidic food and white dry beans as the non-acidic food with and without adding of table salt. Also, measurement the surface morphology of Tefal layer before and after cooking (ten times) in either tomatoes paste or white dry beans with and without salt (sodium chloride) as indication about leaching of prefluorinated compounds from coating through observing the changes that arose on surface compared to the initial conditions.

\section{Material and methods}

\subsection{Non-stick Cookware}

The household cooking utensil used in this study were Tefal cookware $(24 \mathrm{~cm}$ diameter and $30 \mathrm{~mm}$ thickness of Teflon layer which coats the inner surface of utensils), these utensils were purchased from Shedid Eng. Establishment, Cairo, Egypt. 


\subsection{Raw materials}

The raw materials used in this study were divided in two sections. Firstly, $20 \mathrm{~kg}$ of fresh tomatoes (Lycopersicon esculentum) as the acidic foods were purchased from Al-Mollak farm, Abo-Hammad, Sharkia governorate, Egypt. The fresh fruits were harvested in plastic basket after sorted for color, firmness, and lack of blemishes, and then immediately transported to the laboratory and stored in refrigerator at $5 \pm 20 \mathrm{C}$ till further treatments. Secondly, $10 \mathrm{~kg}$ of white dry beans as non- acidic foods were purchased from the local market, Nasr city, Cairo, Egypt, and then stored in the ambient temperature $(25 \pm 30 \mathrm{C})$ further treatments and analysis after transport to the laboratory.

\subsection{Chemicals and reagents}

Sodium salt (sodium chloride) were obtained from, Cairo, Egypt. PFOS: The standards of perfluorooctane sulfonate, PFOA: perfluorooctanoic acid, were purchased from AccuStandard, 153 Inc., New Haven, CT, USA as individual (50 mg) or mixture standards at a concentration of $100 \mu \mathrm{g} / \mathrm{mL}$. All solvents (Methanol, dichloromethane, hexane and acetonitrile) used for the extraction and analysis PAHs were residue-analysis grade $99.9 \%$ purity and obtained from Fisher Scientific (Fair Lawn, NJ, USA).

\subsection{Sample preparation}

All tested samples were prepared in Laboratory of Food Science and Technology Department, Faculty of Agriculture, AL-Azhar University, Cairo, Egypt.

\subsubsection{Tomato pulp preparation}

$20 \mathrm{~kg}$ of fresh tomatoes were divided into 20 patches $(1 \mathrm{~kg}) ; 10$ of them were used without salt, other patches were used with salt. Tomatoes fruit were chopped into pieces with knife and ground into rough pulp using a blender (Braun AG Frank, 40-60 Hz /400W, Tipe MX 32, No. 4142, German). Subsequently, pulp was passed through a finisher (0.5mm screen) to remove skins and seeds. Each part of tomato pulp was cooked in tested Tefal utensil.

\subsubsection{White dry beans preparation}

$10 \mathrm{~kg}$ of white dry beans were divided into 20 patches $(500 \mathrm{~g}) ; 10$ of them were used without salt, other patches were used with salt. Each patch of white dry beans was soaked in $1 \mathrm{~L}$ of distilled water for $180 \mathrm{~min}$. prior to cooking.

\subsection{Samples cooking}

To study the effect of prolonged use (repeating 10 times) on leaching PFOA and PFOS compounds of non-stick tefal utensils to food-contact.

\subsubsection{Tomato pulp cooking}

The first patch of tomato pulp which previously prepared was cooked in tested Tefal utensil with the continuous stirring till to reach 25\% TSS (total soluble solids), after that the second patch of tomato pulp is return cooking in the same Tefal utensil until the same result is achieved. Thus, the other tomato pulp samples are cooked in the same container to reach the same concentration (25\% TSS). The same procedure is carried out in another Tefal utensil for 10 samples of tomato pulp in the same way, but with the addition of $5 \mathrm{~g}$ salt $(\mathrm{NaCl})$ with each sample before cooking. Finally, 20 samples of produced tomatoes paste are kept under frozen storage condition at $-18^{\circ} \mathrm{C}$ till analysis.

\subsubsection{White dry beans cooking}

10 samples of white dry beans after soaking are cooked without salt $(\mathrm{NaCl})$ with $1 \mathrm{~L}$ of distilled water in tested Tefal utensil with the continuous stirring each period. The same cookware were reused in nine consecutive cooking processes with the same previous procedure of soaked white dry beans, while the other samples (10 samples) were cooked with salt $(5 \mathrm{~g})$ in another Tefal utensil as the same way until to achieve the adequate stewing of white dry beans. All tested samples kept in a glass bottles under frozen storage condition (at $-18^{\circ} \mathrm{C}$ ) till analysis.

\subsection{Analysis of tefal layer surface}

A small square shapes were cut from the tested utensils coated with Tefal layer by dimensions of $0.5-1 \mathrm{~cm}$ as shown in the figure (1) in order to examine the Tefal layer by using X- Ray diffraction (XRD), X-Ray analysis (EDX) and Environmental Scanning Electron Microscopy (ESEM) in the Central Laboratory of the Science Faculty, Al - Azhar University, Cairo, Egypt. The fluorinated compounds in tested samples were measured by using $X$ - ray diffraction measurements to test their amorphous nature using Philips Analytical X-Ray diffraction system, type PW3710 based 
with $\mathrm{Cu}$ tube anode of wave length $\mathrm{K} \alpha 1=1.54 \mathrm{~A}^{\circ}$ and $\mathrm{K} \alpha 2=1.54439 \mathrm{~A}^{\circ}$. The generator tension was $40 \mathrm{KV}$, and the generator current was $30 \mathrm{~mA}$. The start angle $(2 \theta)$ was $10 \mathrm{o}$, and the end angle was $70^{\circ}$, while the step size $(2 \theta)$ was 0.02 , and the time step was $1.0 \mathrm{sec}$.
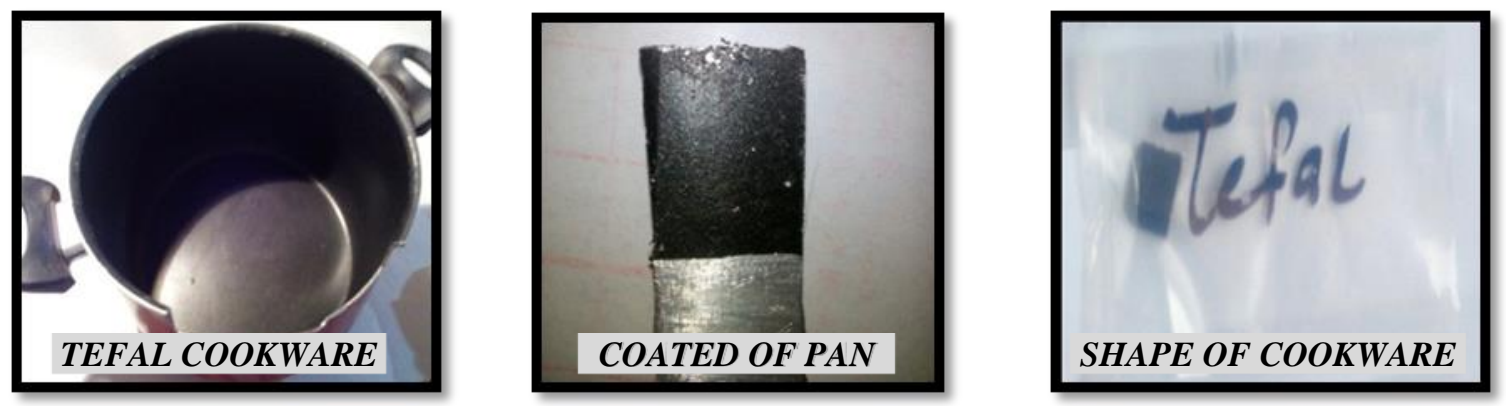

Figure 1 The samples of Tefal coated cookware used in this study

Also, the major and minor elements in tested samples were determined by using X-ray microanalysis (Module Oxford 6587 INCA $x$-sight) attached to JEOL JSM-5500 LV scanning electron microscopy at 20KV after gold coating using SPIModule sputter coater.

In addition, the surface morphology of Tefal layer was measured before and after cooking (ten times) in either tomatoes paste or white dry beans with and without salt (sodium chloride) by using Environmental Scanning Electron Microscopy (ESEM). This measured gives an indication about leaching of chemicals from coating through observing the changes that arose on surface compared to the initial condition.

\subsection{Extraction and determination of PFOA and PFOS compounds in cooked samples}

A pressurized apparatus was used, Accelerated Solvent Extractor (ASE) Model 350, Dionex corporation, Sunnyvale, CA, USA. Mixture of ethanol/water 1:9 was used to simulate watery and acidic foods, and a mixture of 19:1 ethanol/water was used to simulate fatty or oily foods [26]. One obstacle to studying of migration perfluorochemicals used in foodcontact is the difficulty in measuring these substances by routine conventional analytical techniques such as GC/MS or LC-UV [24]. Due to many perfluorochemicals used in food-contact substances are not detectable by these conventional methods. While, liquid chromatography-mass spectrophotometer (LC/MS or LS/MSMS) analytical technique can be suitable to determine of potential migration from perfluoro coatings of tefal cookware. [3, 7, 27].

\subsection{Statistical analysis}

All obtained data are expressed as mean \pm standard deviation. The statistical was performed by using a one-way analysis of variance (ANOVA) followed by Duncan's test according to the procedure of [28] using SPSS version 16 (computer program).

\section{Results and discussion}

\subsection{The accuracy of LC-MS procedure for the quantitative determination of tested perfluorinated compounds in chosen foods}

Before analyzing the actual samples of cooked tomato paste and white dry beans, the efficiency of the analytical method used for the quantitative determination of tested perfluorinated compounds in chosen foods was evaluated via the recovery experiments. The recovery experiments were performed by spiking uncooked tomato and white dry beans samples. Recovery (\%) of PFOS and PFOA compounds in spiked tomato and white dry beans samples analyzed by LCMS procedure were showing in (Table 1). 
Table 1 Recovery (\%) of perfluorinated compounds in spiked tomato and white dry beans samples analyzed by LC-MS procedure

\begin{tabular}{llll}
\hline $\begin{array}{l}\text { Perfluorinated } \\
\text { Compounds }\end{array}$ & $\begin{array}{l}\text { Perfluorinated Compounds } \\
\text { Spiking level (ppb) }\end{array}$ & $\begin{array}{l}\text { Tomatoes } \\
\text { Recovery (\%) }\end{array}$ & $\begin{array}{l}\text { Beans } \\
\text { Recovery (\%) }\end{array}$ \\
\hline PFOS & 100 & 97.89 & 94.81 \\
PFOA & 100 & 96.43 & 94.29 \\
\hline
\end{tabular}

\subsection{Determination of perfluorinated compounds present in cookware teflon layer by using $X$ - Ray diffraction} (XR-D)

The Teflon layer in tefal cookware was analyzed by using XR-D, the obtained data are recorded in Table (2), from these results, it could be observed that the most prevalent perfluorinated compounds in tefal layer was carbon fluoride which accounted $82 \%$, followed by 1, 4-bis tetrafluorobenzene (pentafluorophenylethyl), which was recorded $18.0 \%$. The present results are agreement with the data obtained by [29, 30, 31].

Table 2 Perfluorinated compounds presented in cookware Tefal layer determined by XR-D

\begin{tabular}{lc}
\hline Perfluorinated compounds & $\mathbf{( \% )}$ \\
\hline 1, 4-bis tetrafluorobenzene (pentafluorophenylethyl) & 18 \\
Carbon fluoride & 82 \\
\hline
\end{tabular}

\subsection{Microanalysis of teflon layer which coating the tested tefal cookware by using X- Ray Microanalysis (EDX)}

The main elements in the coating layer of tested tefal cookware, which analyzed by using X-ray microanalysis are presented in Table (3) and Figure (2). From the obtained data, it could be exhibited that the fluoride (F) was the most abundant elements, which was represented $79.623 \%$, followed by the carbon element (C) which was the minor element found in the coating layer of tested tefal cookware (18.60\%). This result may be explained by the fact that F and C elements are the main elements in the fluoropolymer-coating in tefal layer [31]. On the other side, Si and K were found to be as 0.280 and 0.110 , respectively. Meanwhile, the trace elements found in this layer were $\mathrm{Ti}, \mathrm{Cl}, \mathrm{Ca}$ and $\mathrm{S}$, which represented $0.080,0.47,0.033$ and 0.024 , respectively.

Table 3 The elements presented in the coating layer of tested tefal cookware

\begin{tabular}{llllllllll}
\hline \multicolumn{1}{c}{ Main elements found in the coating layer of tested tefal cookware } \\
\hline Elements & $\mathrm{F}$ & $\mathrm{C}$ & $\mathrm{O}$ & $\mathrm{Si}$ & $\mathrm{K}$ & $\mathrm{Ti}$ & $\mathrm{Cl}$ & $\mathrm{Ca}$ & $\mathrm{S}$ \\
Percentage & $79.623 \mathrm{a}$ & $18.600 \mathrm{~b}$ & $1.203 \mathrm{c}$ & $0.280 \mathrm{~d}$ & $0.110 \mathrm{e}$ & $0.080 \mathrm{e}$ & $0.047 \mathrm{f}$ & $0.033 \mathrm{f}$ & $0.024 \mathrm{~g}$ \\
(\%) & \pm 0.314 & \pm 0.322 & \pm 0.045 & \pm 0.020 & \pm 0.017 & \pm 0.020 & \pm 0.006 & \pm 0.010 & \pm 0.003
\end{tabular}

* Mean of triplicate samples result \pm standard error for metals content; the means, within the same row, having different superscripts are significantly varied (at $\mathrm{p} \leq 0.05$ )
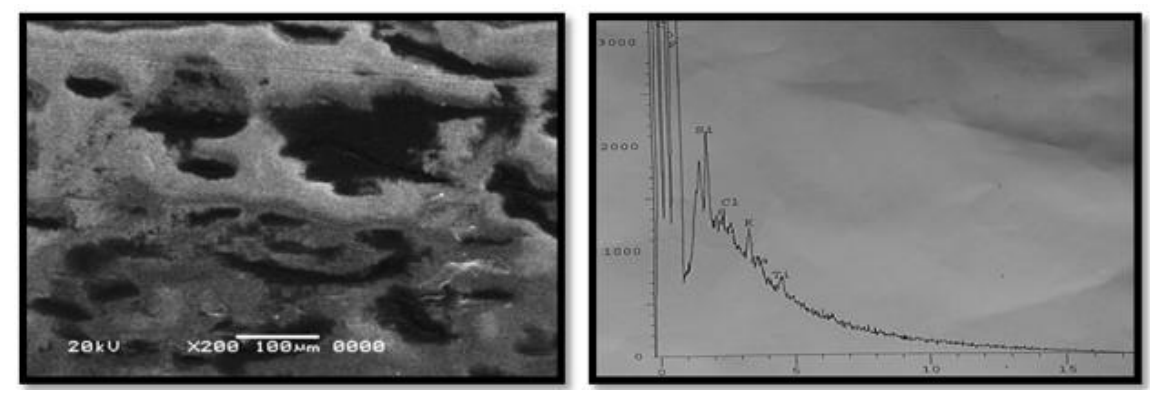

Figure 2 The environmental scanning electron micrographs of the utensil surfaces by using of X-ray microanalysis microanalysis (Module Oxford 6587 INCA x-sight) attached to JEOL JSM-5500 LV scanning electron microscopy at $20 \mathrm{KV}$ after gold coating using SPI-Module sputter coater (EDX). 


\subsection{Surface morphology for coating of cookware before and after cooking}

The results in current investigation ( Figure 3) shows by using the environmental scanning electron micrographs of the surface morphology of Tefal layer before and after cooking (ten times) in either tomatoes paste or white dry beans with and without salt (sodium chloride).

From the obtained results, it could be exhibited that after ten times of cooking in tefal cookware with either tomato paste or white dry beans caused some damage in tefal layer, while this damage was appeared a variable levels between the tested samples. Firstly, the cooked samples with the table salt had the highest damage in the tefal layer than those found in the same cooked samples without salt (in either tomato paste or white dry beans). On the other side, the acidic food (tomato paste) was more than the effect on the damage occurred in the tefal layer as compared with the low acidic food (white dry beans), where the highest damage was found with the tomato paste with the table salt as compared with the other tested samples. The current results revealed that the effect of acidity with the presence of the ions salt led to increasing rate of the corrosion levels in exposure surfaces as reported by [32, 33]. The caused corrosion of coating layer by re-used of tefal cookware can be indicator to release of some chemicals from coating to foods during cooking.
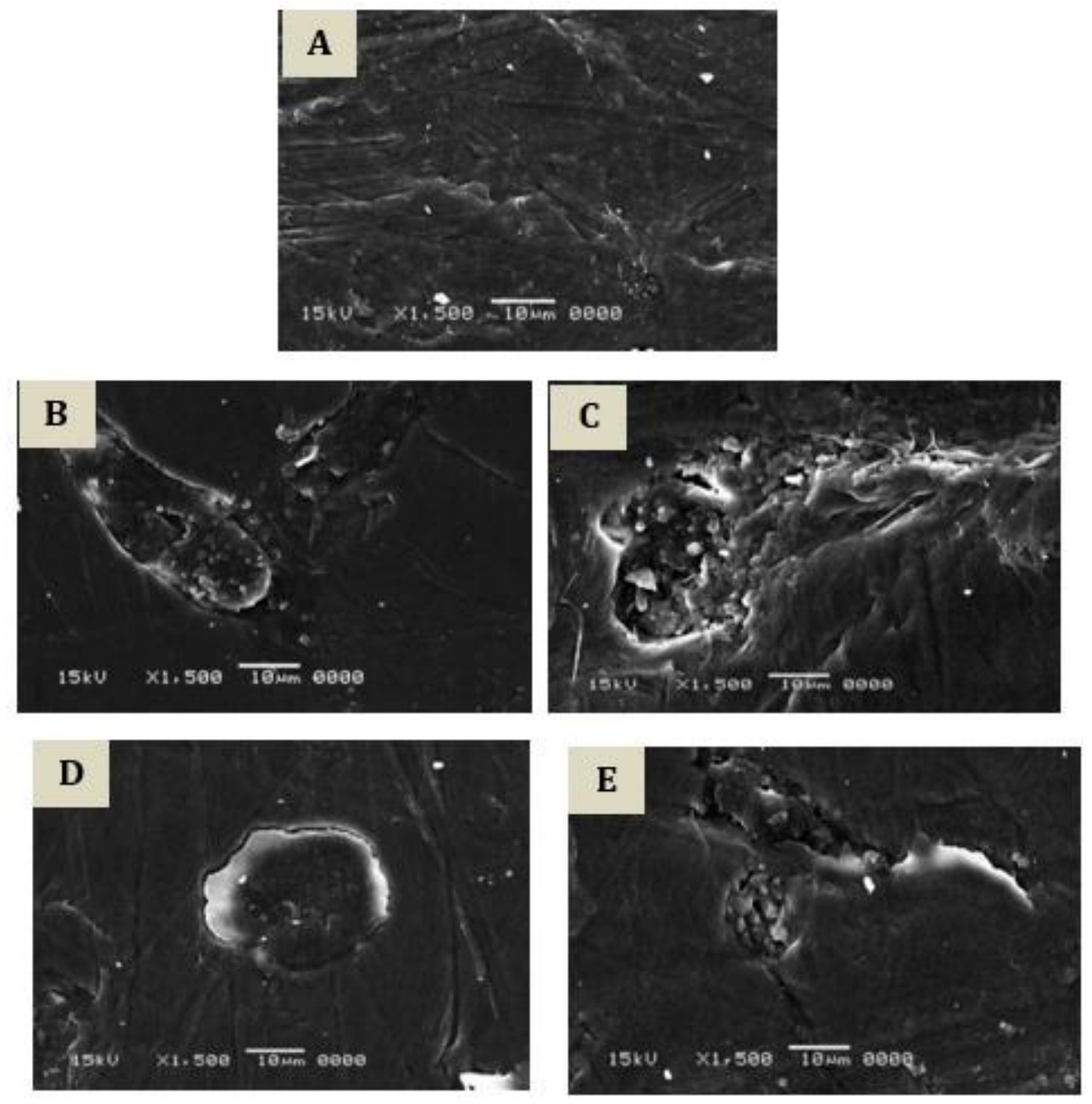

Figure 3 ESEM images of coating surface with and without cooking (ten times): A-ESEM image (coating surface without cooking as blank); B- ESEM image (coating surface after 10 times of cooking for tomato pasta without salt; CESEM image tomato pasta with salt; D- ESEM image white dry beans without salt; E- ESEM image white dry beans with salt. 
AbulFadl et al. / World Journal of Advanced Research and Reviews, 2019, 03(02), 024-035

\subsection{Effect of cooking at different times of tomatoes paste with and without salt on migration of PFOS and PFOA compounds to food-contact from tefal cookware}

The Effect of cooking at different times (repeating 1, 5 and 10 times) of tomatoes paste with and without salt on migration of PFOS and PFOA compounds to food-contact from Tefal Cookware are listed in Table (4), from the obtained data it could be noticed that not detected of either PFOS or PFOA in tomatoes juice (raw tomatoes) without cooking.

Table 4 The Effect of cooking at different times (repeating) of tomatoes pasta with and without salt on migration of PFOS and PFOA compounds to food-contact from Tefal Cookware.

\begin{tabular}{|c|c|c|c|c|}
\hline \multirow{2}{*}{$\begin{array}{l}\text { Cooking times } \\
\text { (repeating) }\end{array}$} & \multicolumn{2}{|c|}{ *PFOS (ng/g) } & \multicolumn{2}{|c|}{ **PFOA (ng/g) } \\
\hline & Without salt & With salt & Without salt & With salt \\
\hline (Row sample) & 0.0 & 0.0 & 0.0 & 0.0 \\
\hline 1 & $13.72^{B c} \pm 0.18$ & $18.30^{A c} \pm 0.001$ & $10.21^{B C} \pm 0.14$ & $16.55^{A c} \pm 0.21$ \\
\hline 5 & $31.22^{B b} \pm 0.20$ & $39.55^{A b} \pm 0.015$ & $26.20^{B b} \pm 0.19$ & $34.52^{A b} \pm 0.11$ \\
\hline 10 & $52.11^{B a} \pm 0.03$ & $60.33^{A a} \pm 0.17$ & $48.44^{B a} \pm 0.23$ & $54.21^{A a} \pm 0.20$ \\
\hline
\end{tabular}

*Row sample: tomatoes juice without cooking; the obtained results are represented the mean of triplicate determination \pm standard error (SE); *the means value of PFOS which having different capital superscripts within the same row are significantly varied (at $\mathrm{p} \leq 0.05$ ); ${ }^{* *}$ the means value of PFOA which having different capital superscripts within the same row are significantly varied (at $\mathrm{p} \leq 0.05)$; means value of repeat cooking time, within the same small letters on the same column are significantly different of $\mathrm{p}<0.05$.

On the other hand, when the tomatoes paste prepared by cooking at different times (1, 5 and 10); both PFOS and PFOA compounds were appeared in all tested samples after cooking with and without salt. Therefore, the amounts of PFOS or PFOA in the tested samples with salt were higher than that found in the tested samples without salt at all repeat cooking (1, 5 and 10). Also, considerable significant differences in the amount of either PFOS or PFOA were observed between the tested samples with and without salt at all different cooking times. Whereas, the maximum amount of PFOS $(60.33 \mathrm{ng} / \mathrm{g})$ was observed in tested tomatoes paste with salt after ten repeat of cooking, which was higher than the amount of PFOS $(52.11 \mathrm{ng} / \mathrm{g})$ in tested tomatoes paste without salt after the corresponding times of cooking. On the other side, the same behavior was also observed in the amount of PFOA after ten repeated cook in the same tested samples, which was recorded $54.21 \mathrm{ng} / \mathrm{g}$ with the tested sample with salt versus to $48.44 \mathrm{ng} / \mathrm{g}$ without salt. The present results are in agreement with the data obtained by [32] they reported that when increasing salt concentration in foodcontact, increases the corrosion rate from cookware up to a certain value upon which a decrease is observed to reach a plateau of constant corrosion rates. Also, [34] reported that the corrosion rate in cooking utensils was increased by increasing the addition of salt. In addition, [33] showed that the leaching of cookware metal to food contact depends on constituents and $\mathrm{pH}$ of solution, presence of sodium chloride, immersion time, water composition and alloying elements.

From the same data, it could be also observed that, when the repeat of cooking increased, the amount of either PFOS or PFOA was gradually increased. Thereupon, the amount of PFOS was increment from 13.72 to $52.11 \mathrm{ng} / \mathrm{g}$ without salt, and from 18.30 to $60.33 \mathrm{ng} / \mathrm{g}$ with the salt, also the amount of PFOA was increased from 10.21 to $48.44 \mathrm{ng} / \mathrm{g}$ without salt, and from 16.55 to $54.21 \mathrm{ng} / \mathrm{g}$ with salt as the repeated cook increase from one to ten times; respectively.

These results may be explained by the fact that, the increasing of perflorounated compounds is clearly repeat cookingdependent, as it increases with increasing the repeating times of cooking. Also, it is interesting to note that, the repeating times of cooking with the salt in the tested samples caused a highly obvious migration of PFOS or PFOA than the same times of cooking without salt in the tested samples.

\subsection{Effect of cooking at different times of white dry beans with and without salt on migration of PFOS and PFOA compounds to food-contact from tefal cookware}

The Effect of the repeating times of cook on the migration of PFOS and PFOA compounds from Tefal Cookware to white dry beans with and without salt are shown in Table (5). From the obtained results, it could be exhibited that the amounts of both PFOS and PFOA were progressively increase in the tested samples as the repeating times of cooking increased from one to ten times. Also when used the salt (sodium chloride) with the tested samples, the amounts of both PFOS and PFOA were increase as compared with the same tested samples without salt. 
AbulFadl et al. / World Journal of Advanced Research and Reviews, 2019, 03(02), 024-035

Table 5 The Effect of cooking at different times (repeating) of white dry beans with and without salt on migration of PFOS and PFOA compounds to food-contact from Tefal Cookware.

\begin{tabular}{lllll}
\hline $\begin{array}{l}\text { Cooking } \\
\text { (repeating) }\end{array}$ & times & \multicolumn{2}{c}{${ }^{* \text { PFOS (ng/g) }}$} & \multicolumn{2}{c}{${ }^{* * P F O A ~(n g / g) ~}$} \\
\cline { 2 - 5 } & Without salt & With salt & Without salt & With salt \\
\hline (Row sample) & 0.0 & 0.0 & 0.0 & 0.0 \\
$\mathbf{1}$ & $13.11^{B C} \pm 0.13$ & $18.08^{A C} \pm 0.19$ & $9.28^{B C} \pm 0.16$ & $16.03^{A C} \pm 0.19$ \\
$\mathbf{5}$ & $29.22^{B b_{ \pm} \pm 0.16}$ & $36.20^{A b_{ \pm}} 0.007$ & $26.11^{B b_{ \pm} \pm 0.004}$ & $33.04^{A b_{ \pm} 0.27}$ \\
$\mathbf{1 0}$ & $50.03^{B a} \pm 0.15$ & $57.24^{A a} \pm 0.09$ & $45.80^{B a} \pm 0.08$ & $51.76^{A a} \pm 0.13$ \\
\hline
\end{tabular}

*Row sample: white dry beans without cooking; the obtained results are represented the mean of triplicate determination \pm standard error (SE); *the means value of PFOS which having different capital superscripts within the same row are significantly varied (at $p \leq 0.05$ ); ${ }^{* *}$ the means value of PFOA which having different capital superscripts within the same row are significantly varied (at $p \leq 0.05)$; Each mean value of repeat cooking time, within the same small letters on the same column are significantly different of $\mathrm{p}<0.05$.

From the previous data, it could be indicated that there are obvious significant differences $(\mathrm{P}>0.05)$ between the tested samples cooked with the salt and without salt for content of both PFOS and PFOA at one or 5 or 10 times of repeat cooking. The current results are coincidence with the data obtained by [32] which they reported that the increasing salinity of the medium increases aluminum leaching for both Indian and Egyptian samples under investigation with up to an effect of 6 times more than at salt-free conditions. Likewise, the effect of addition salt to food contact on leaching of cookware metal was also investigated by [35]. Their results were relatively comparable with the present data.

With regards the alteration in the amounts of both PFOS and PFOA in the tested samples as affected by the repeat cooking in the Tefal cookware as evident in Table (5), there are significant differences in all tested samples with and without salt for the amounts of both PFOS and PFOA between the first to $5^{\text {th }}$ cooking, and also between $5^{\text {th }}$ to $10^{\text {th }}$ repeat cooking. Whereas after the first of cooking, the amount of PFOS in the tested samples was accounted 13.11 and 18.09 $\mathrm{ng} / \mathrm{g}$, while after $5^{\text {th }}$ repeat cooking it was presented 29.22 and $36.20 \mathrm{ng} / \mathrm{g}$, then after $10^{\text {th }}$ repeat cooking it was recorded 50.03 and $57.24 \mathrm{ng} / \mathrm{g}$, without and with salt; respectively. On the other side, the amount of PFOA was recorded 9.28 and $16.03 \mathrm{ng} / \mathrm{g}$ after the first cooking, and it was represented 26.11and $33.04 \mathrm{ng} / \mathrm{g}$ after $5^{\text {th }}$ repeat of cooking, while it was found 45.57 and $51.76 \mathrm{ng} / \mathrm{g}$ after $10^{\text {th }}$ repeat of cooking without and with salt; respectively.

\subsection{Effect of repeated cooking at different times of tested foods with and without salt on contents of PFOS and PFOA compounds to food-contact from tefal cookware}

The Effect of repeated cooking at different times (1, 5 and 10) of tested foods (tomatoes paste and white dry beans) with and without salt on contents of PFOS and PFOA compounds to food-contact from Tefal Cookware are listed in Table (6).

As shown in the obtained results (Table 6), it could be mentioned that both PFOS and PFOA in the acidic tested samples (tomatoes paste) after all repeating times of cooking (1, 5 and 10) were more than those found in non- acidic tested samples (white dry beans), especially with PFOS content. In this concern, the amount of PFOS after 10 times of repeat cooking of tomatoes paste samples was 52.11 and $60.33 \mathrm{ng} / \mathrm{g}$ as compared to 50.03 and $57.24 \mathrm{ng} / \mathrm{g}$ for white dry beans without and with salt; respectively. Also after 10 times of repeat cooking, the amount of PFOA of tomatoes paste as the acidic food was 48.44 and $54.21 \mathrm{ng} / \mathrm{g}$ versus to 45.80 and $51.76 \mathrm{ng} / \mathrm{g}$ of white dry beans without and with salt; respectively. These results are accordance with the data obtained by [33,34,36]. Also, [37] showed that tomatoes sauce and beans foodstuff have high potentials of leaching metals from cookware possibly due to $\mathrm{pH}$ and contact time.

From previous discussion, it could be observed that, when the repeat of cooking increased from 1 up to 10 times, the amounts of Perfluorinated compounds (PFOS and PFOA, especially PFOS) were progressively increased in the food contact (tomatoes paste or white dry beans) from the tefal cookware. On the other side, the addition of table salt to the tested samples at all repeat of cooking ( 1 or 5 or 10 times) caused a highly leaching of perfluorinated from the tefon layer to food-contact more than the same tested samples at the same conditions without salt. Therefore, the acidic food such as tomatoes paste was more effect on the amounts of both PFOS and PFOA in the food-contact than the non-acidic food. 
Table 6 Effect of repeated cooking at different times of tested foods with and without salt on contents of PFOS and PFOA compounds to food-contact from Tefal Cookware.

*PFOS concentration

**PFOA concentration

\begin{tabular}{|c|c|c|c|c|c|c|c|c|}
\hline \multirow[t]{2}{*}{ Repeat of cooking (times) } & 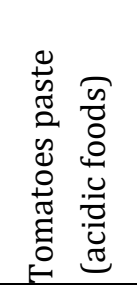 & 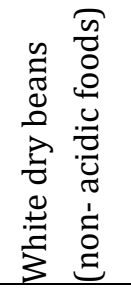 & 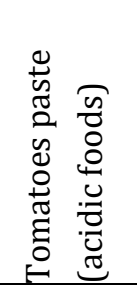 & 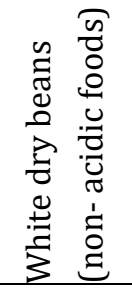 & 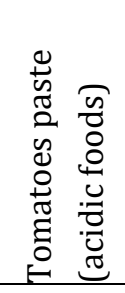 & 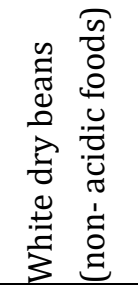 & 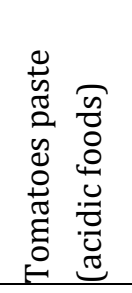 & 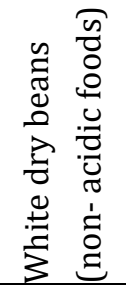 \\
\hline & \multicolumn{2}{|c|}{ Without salt } & \multicolumn{2}{|c|}{ With salt } & \multicolumn{2}{|c|}{ Without salt } & \multicolumn{2}{|c|}{ With salt } \\
\hline \multirow[t]{2}{*}{1} & $13.72^{\mathrm{Bc}}$ & $13.11^{\mathrm{Bc}}$ & $18.30 \mathrm{Ac}$ & $18.08 \mathrm{Ac}$ & $10.21 \mathrm{Bc}$ & $9.28^{\mathrm{Cc}}$ & $16.55 \mathrm{Ac}$ & $16.03 \mathrm{Ac}$ \\
\hline & \pm 0.18 & \pm 0.13 & \pm 0.001 & \pm 0.19 & \pm 0.14 & \pm 0.16 & \pm 0.21 & \pm 0.19 \\
\hline \multirow[t]{2}{*}{5} & $31.22^{\mathrm{Cb}}$ & $29.22 \mathrm{Db}$ & $39.55^{\mathrm{Ab}}$ & $36.20^{\mathrm{Bb}}$ & $26.20^{\mathrm{Cb}}$ & $26.11^{\mathrm{Cb}}$ & $34.52 \mathrm{Ab}$ & $33.04 \mathrm{Bb}$ \\
\hline & \pm 0.20 & \pm 0.16 & \pm 0.015 & \pm 0.007 & \pm 0.19 & \pm 0.004 & \pm 0.11 & \pm 0.27 \\
\hline \multirow[t]{2}{*}{10} & $52.11 \mathrm{Ca}$ & $50.03 \mathrm{Da}$ & $60.33 \mathrm{Aa}$ & $57.24 \mathrm{Ba}$ & $48.44 \mathrm{Ca}$ & $45.80 \mathrm{Da}$ & $54.21 \mathrm{Aa}$ & $51.76^{\mathrm{Ba}}$ \\
\hline & \pm 0.03 & \pm 0.15 & \pm 0.17 & \pm 0.09 & \pm 0.23 & \pm 0.08 & \pm 0.20 & \pm 0.13 \\
\hline
\end{tabular}

PFOS: perfluorooctane sulfonate, PFOA: perfluorooctanoic acid, the obtained results are represented the mean of triplicate determination \pm standard error (SE); *the means value of PFOS which having different capital superscripts within the same row are significantly varied (at $\mathrm{p} \leq 0.05$ ); ${ }^{* *}$ the means value of PFOA which having different capital superscripts within the same row are significantly varied (at $\mathrm{p} \leq 0.05$ ); Each mean value of repeat cooking time, within the same small letters on the same column are significantly different of $\mathrm{p}<0.05$. 


\section{Conclusion}

The presented study was carried on Tefal cookware in two trends. The first trend, the coating of cookware was analyzed by Xray Diffraction (XRD) and X-ray microanalysis (EDX). As well as environmental scanning electron microscopy (ESEM) was used to observed the changes that arose on surface by cooking. ESEM images of coating surface observed that repeat of cooking in Tefal cookware have been caused some damage of coating. The second trend, effect of repeat cooking times on migration of PFOS and PFOA compounds from Tefal cookware to cooked food with and without salt. It is concluded that salt-cooked tomato samples had highest concentrations of PFOS followed PFOA throughout usage. Besides that, content of cooked food from PFOS and PFOA compounds increased with repeat of cooking times.

\section{Compliance with ethical standards}

\section{Acknowledgments}

The Authors thank the Food Sci. \& Tech. Dept., Faculty of Agriculture, Al-Azhar Univ. Egypt for supporting this research in all stages. Also, Authors deeply thank Chromatographic Analysis Unit, College of Food and Agricultural Sciences, King Saud University, Kingdom of Saudi Arabia and Prof. John B. Sapp, Chem. Dept. Texas Southern Univ. Houston Texas, USA for supporting the analysis of PFOS and PFOA.

\section{Disclosure of conflict of interest}

Authors have declared that no competing interests exist.

\section{References}

[1] Tseng CL, Liu LL, Chen, CM and Ding WH. (2006). Analysis of perfluorooctanesulfonate and related fluorochemicals in water and biological tissue samples by liquid chromatography-ion trap mass spectrometry. J. Chromatogr. A., 1105, 119-126.

[2] Lau C, Anitole K, Hodes C, Lai D, Pfahles-Hutchens A and Seed J. (2007). Perfluoroalkyl acids: a review of monitoring and toxicological findings. Toxicol. Sci., 99, 366-394.

[3] Sungur S. (2017). Dietary exposure to perfluorooctanoic acid (PFOA) and perfluorooctane sulfonic acid (PFOS): a review of recent literature, 1556-9551.

[4] Kissa DP, Kiryuhina IP, Kima VM, Buznikb LN, Ignat'evac VG, Kuryavyic SG and Sakharov E. (2001). Fluorinated surfactants and repellents. New York: Marcel Dekker.

[5] Post GB, Cohn PD and Cooper KR. (2012). Perfluorooctanoic acid (PFOA), an emerging drinking water contaminant: a critical review of recent literature. Environmental research, 116, 93-117.

[6] Surma M, Wiczkowski W, Zieliński H and Cieślik E. (2015). Determination of selected perfluorinated acids (PFCAs) and perfluorinated sulfonates (PFASs) in food contact materials using LC-MS/MS. Packaging technology and science, 28, 789-799.

[7] Choi HI, Bae JC, Choi SP and Kim MK. (2018). Perfluorinated compounds in food simulants after migration from fluorocarbon resin-coated frying pans, baking utensils and non-stick baking papers on the Korean market. 19393229.

[8] Yeung LWY, Taniyasu S, Kannan K, Xu DZY, Guruge KS, Lam PKS and Yamashita N. (2009). An analytical method for the determination of perfluorinated compounds in whole blood using acetonitrile and solid phase extraction methods. J. Chromatogr. A, 1216(25), 4950.

[9] EFSA (2008). Perfluorooctanesulfonate (PFOS), perfluorooctanoic acid (PFOA) and their salts. Scientific opinion of the panel on contaminants in the food chain. The EFSA journal, 653, 1-131.

[10] Larsen PB and Giovalle E. (2015). Perfluoroalkylated substances: PFOA, PFOS and PFOSA. Environmental project no. 1665 .

[11] Biegel LB, Hurtt ME, Frame SR, O'Connor JC and Cook JC. (2001). Mechanisms of extrahepatic tumor induction by peroxisome proliferators in male CD rats. Toxicol Sci., 60, 44-55. 
[12] OECD. (2002). Hazard Assessment of Perfluorooctane Sulfonate (PFOS) and its Salts: Paris, Report ENV/NV/JM/RD. (2002)17/FINAL. Organisation for Economic Co-operation and Development.

[13] EFSA. (2012). Perfluoroalkylated substances in food: occurrence and dietary exposure. European Food Safety Authority Journal, 10 (6), 2743.

[14] Danish EPA. (2013). Survey of PFOS, PFOA and other perfluoroalkyl and perfluoroalkyl substances. Danish Environmental Protection Agency.

[15] Surma M and Zieliński H. (2015). What do We Know about the Risk Arising from Perfluorinated Compounds. Pol. J. Environ. Stud., 24(2), 449-457.

[16] Lilienthal H, Dieter HH, Holzer J and Wilhelm M. (2017). Recent experimental results of effects of perfluoroalkyl substances in laboratory animals - Relation to current regulations and guidance values. International Journal of Hygiene and Environmental Health.

[17] Sinclair E, Kim SK, Akinleye HB and Kannan K. (2007). Quantitation of gas-phase perfluoroalkyl surfactants and fluorotelomer alcohols released from nonstick cookware and microwave popcorn bags. Environmental Science and Technology, 41, 1180-1185.

[18] Joyce MA, Dinglasan-Panlilio MJ and Mabury SA. (2006). Significant residual fluorinated alcohols present in various fluorinated materials. Environ. Sci. Technol., 40, 1447-1453.

[19] Martin JW, Ellis DA, Mabury SA, Hurley MD and Wallington TJ. (2006). Atmospheric chemistry of perfluoroalkanesulfonamides: kinetic and product studies of the $\mathrm{OH}$ radical and $\mathrm{Cl}$ atom initiated oxidation of $\mathrm{N}$ ethyl perfluorobutanesulfonamide. Environ. Sci. Technol., 40, 864-872.

[20] Prevedouros K, Coudins IT, Buck RC and Korzeniowski SH. (2006). Source fate and transport of perfluorocarboxylates. Environ. Sci. Technol., 40, 32-44.

[21] Jogsten IE, Perelló G, Llebaria X, Bigas E, Martí-Cid R, Karrman A and Domingo JL. (2009). Exposure to perfluorinated compounds in Catalonia, Spain, through consumption of various raw and cooked foodstuffs, including packaged food. Food and Chemical Toxicology, 47, 1577-1583.

[22] Zafeiraki E, Costopoulou D, Vassiliadou I, Bakeas E and Leondiadis L. (2014). Determination of perfluorinated compounds (PFCs) in various foodstuff packaging materials used in the Greek market. Chemosphere, 94, 169176.

[23] Sajid M and Ilyas M. (2017). PTFE-coated non-stick cookware and toxicity concerns: a perspective. Environ. Sci. Pollut. Res., 24, 23436-23440.

[24] Begley TH, White K, Honigfort P, Twaroski ML, Neches R and Walker RA. (2005). Perfluorochemicals: Potential sources of and migration from food packaging. Food Add. Contam., 22, 1023-1031.

[25] Tittlemier SA, Pepper K and Edwards L. (2006). Concentrations of perfluorooctane sulfonamides in Canadian total diet study composite food samples collected between 1992 and 2004. Journal of Agricultural and Food Chemistry, 54 (21), 8385-8389.

[26] US FDA “Guidance for Industry - Preparation of Food Contact Notifications and Food Additive Petitions for Food Contact Substances: Chemistry Recommendations" Final Guidance, April 2002, Appendix I.

[27] Bononi M and Fernando T. (2007). Identification of Perfluorooctanoic Acid Release from Commercial Coated Cooking Pans by Liquid Chromatography Coupled to Electrospray Ionization Tandem Mass Spectrometry. American Journal of Agricultural and Biological Sciences, 2(3), 191-194.

[28] Armitage P. (1971). Statistical Methods in Medical Research. Blackwell Scientific Publications, London, Bajwa UK and Sandhu KS. 2011. Effect of handling and processing on pesticide residues in food-are view. J. Food Sci. Technol, 5(2), 734-742.

[29] Hale P, Turgeon S, Horny P, Lewis F, Brack N, Riessen GV, Pigram P and Mantovani D.(2008). X-ray Photoelectron Emission Microscopy and Time-of-Flight Secondary Ion Mass Spectrometry Analysis of Ultrathin Fluoropolymer Coatings for Stent Applications. Langmuir, 24, 7897-7905.

[30] Kim IP, Buznik VM, Ignat'eva LN, Kuryavyic VG and Sakharov SG. (2009). Radiation-Chemical Synthesis of Tetrafluoroethylene Telomers and Their Use for Preparation of Thin Protective Fluoropolymer Coatings. Russian Journal of General Chemistry, 79(3), 589-595. 
[31] Damdhar VS, Pan KN, Peshw DR and Gogte CL. (2015). To Investigate the Wear Mechanism on Cryogenic Treatment of PTFE-Mica Filled Composite Coatings in Cookware. Trans Indian Inst. Met., 68(4), 611-621.

[32] Al Zubaidy EA, Mohammad F and Bassioni G. (2011). Effect of $\mathrm{pH}$, salinity and temperature on aluminum cookware leaching during food preparation. Int. J. Electrochem. Sci. 6, 6424 -6441.

[33] Al Juhaiman LA. (2012). Estimating aluminum leaching from aluminum cookware in different vegetable extracts. Int. J. Electrochem. Sci, 7, 7283 - 7294.

[34] Mohammad FS, Al Zubaidy EAH and Bassioni, G. (2011). Effect of aluminum leaching process of cooking wares on food. Int. J. Electrochem. Sci, 6, $222-230$.

[35] Gupta SS, Baksi A, Subramanian V and Pradeep T. (2016). Cooking induced corrosion of metals. ACS Sustainable Chemistry \& Engineering 1-23.

[36] Weidenhamer JD, Fitzpatrick MP, Biro AM, Kobunski PA, Hudson MR, Corbin RW and Gottesfeld P. (2016). Metal exposures from aluminum cookware: An unrecognized public health risk in developing countries. Science of the Total Environment.

[37] Ogidi M, Sridhar MKC and Coker AO. (2017). A Follow-Up Study Health Risk Assessment of Heavy Metal Leachability from Household Cookwares. J Food Sci Toxicol 1, 1-3.

\section{How to cite this article}

AbulFadl MM, Sharaf AM, Mostafa MM and El-Saeid MH. (2019). Impact of household cooking on release of fluorinated compounds PFOA and PFOS from tefal coated cookware to foods. World Journal of Advanced Research and Reviews, $3(2), 24-35$. 